\title{
Les inondations en Serbie vues de l'espace
}

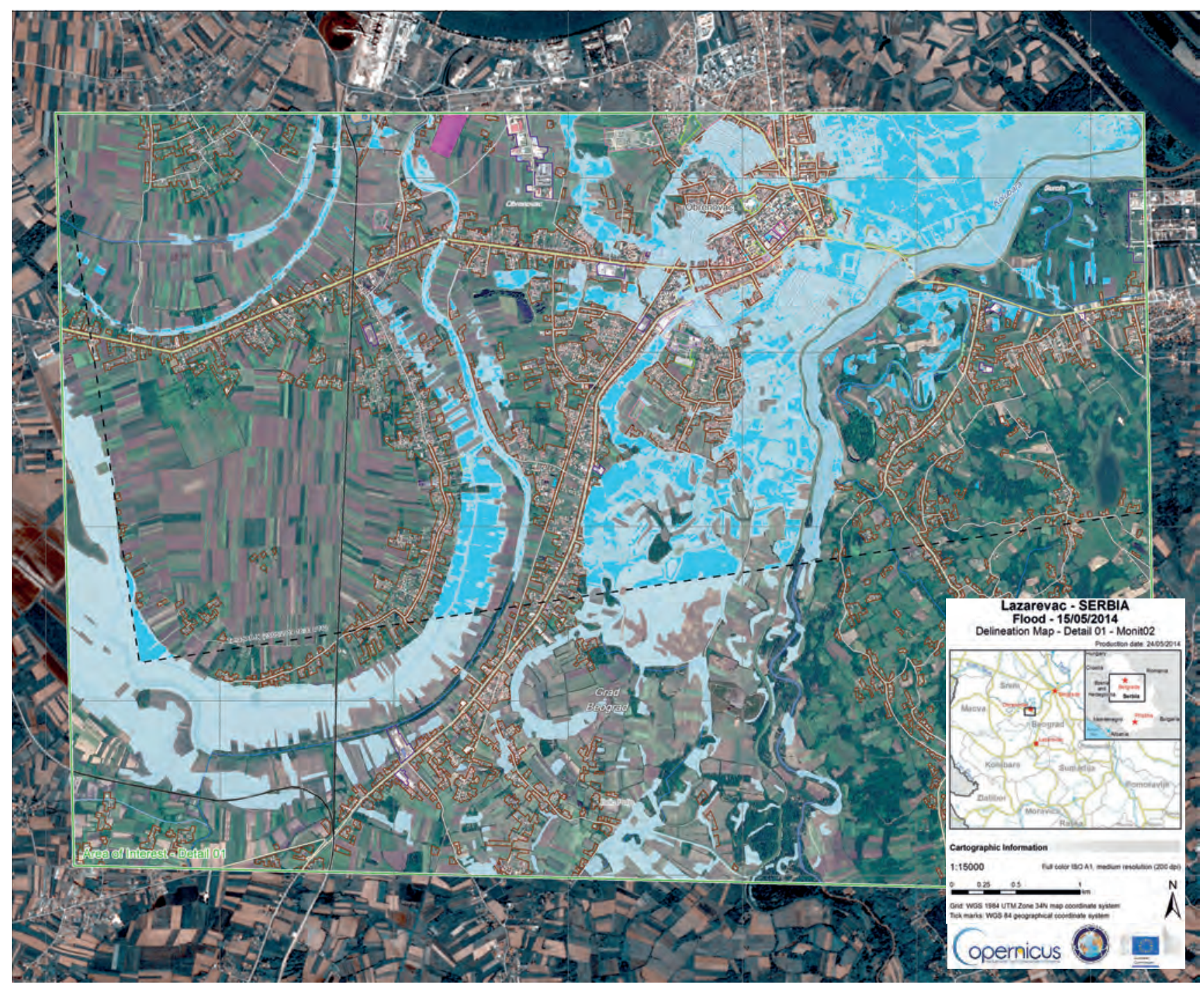

TerraSAR-X (c) 2014 German Aerospace Center (DLR), 2014 Airbus Defence and Space / Infoterra GmbH (c Spot data (c) Airbus Defence and Space.

Entre le 14 et le 20 mai 2014, le nord-ouest des Balkans a subi des pluies diluviennes (parfois 150 à 200 mm en 2 jours) qui ont provoqué des inondations catastrophiques en Serbie, en Bosnie et en Croatie. Environ 1,6 million d'habitants ont été affectés et on a déploré près de 80 victimes.

L'image montre la région d'Obrenovac, une ville de Serbie située à $30 \mathrm{~km}$ au sud-ouest de Belgrade, en bordure de la rivière Save. Les zones en bleu soutenu sont les zones inondées à la date du 23 mai, déterminées par le radar SAR du satellite TerraSAR-X dans la région limitée par les pointillés noirs. Les zones en bleu pâle sont les zones inondées à la date du 21 mai, déterminées par l'imageur optique du satellite Spot-6. On observe qu'une partie substantielle de la ville d'Obrenovac a été inondée. Une image obtenue par Spot-5 en mai 2011, avant les inondations, a servi d'image de référence.

Cette carte a été élaborée par le Service de gestion des urgences du programme européen Copernicus d'observation de la Terre. Elle a été fournie aux autorités de protection civile impliquées dans les opérations de terrain. 


\section{météo}

etclimat

Présente

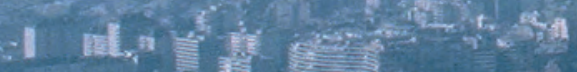

1.

(f)

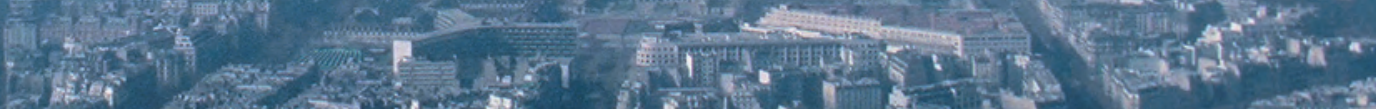

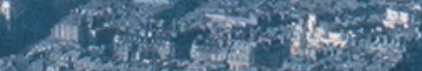

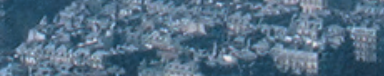

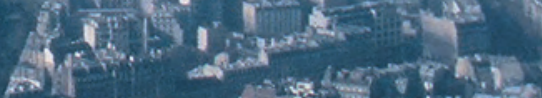

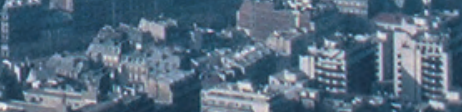

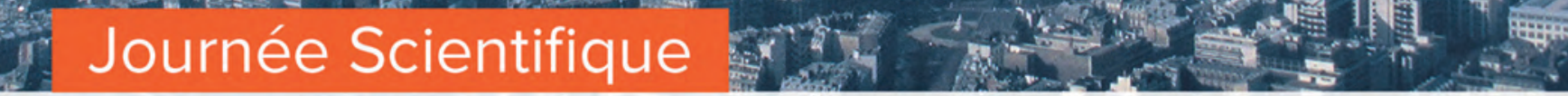

\section{Pollution atmosphérique et impacts sanitaires}

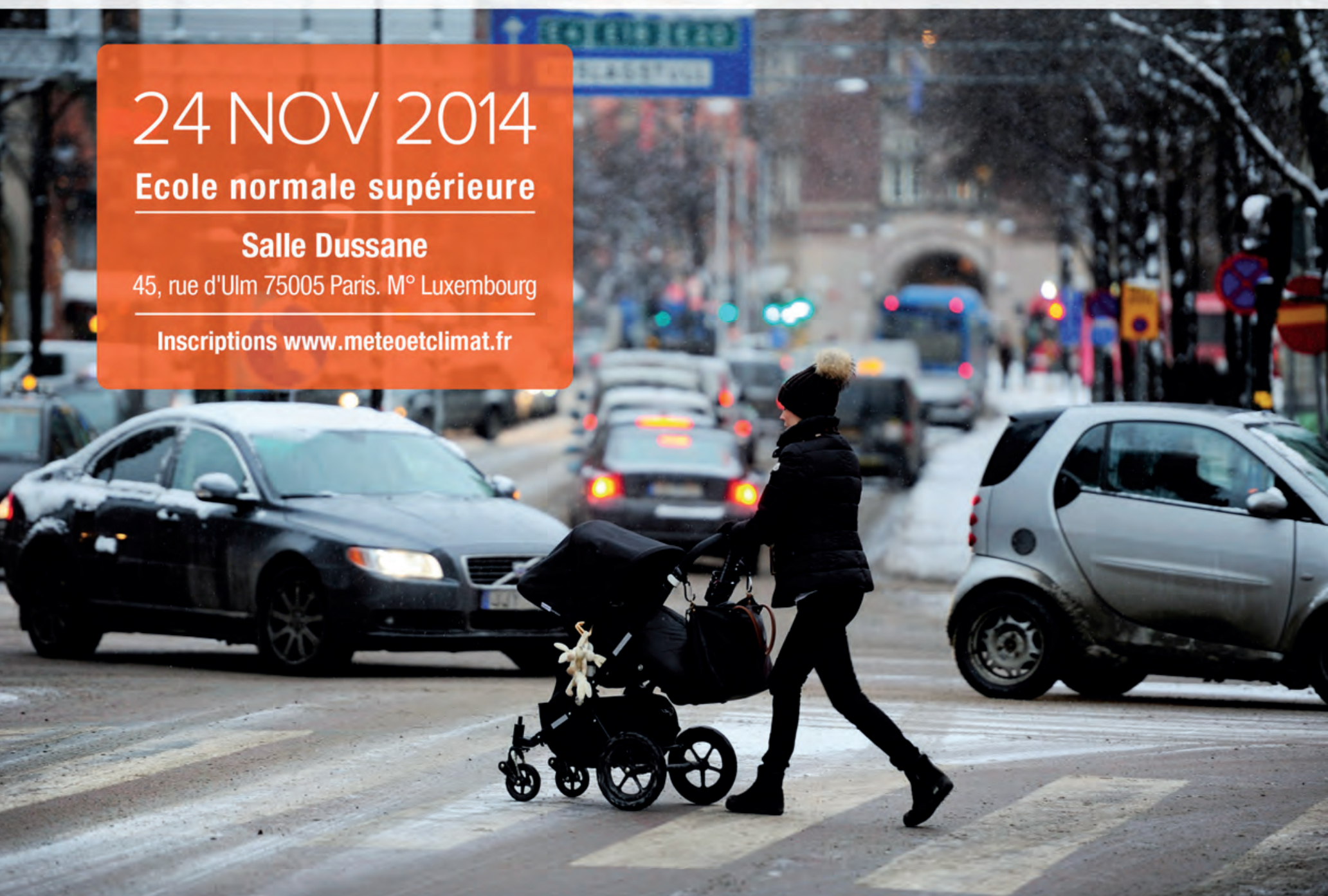

ORGANISÉE PAR

météo

etclimat
EN ASSOCIATION AVEC

$\frac{\sqrt{\text { A日 }}}{\text { ENS }} \begin{aligned} & \text { Département } \\ & \text { des } \\ & \text { Géosiences }\end{aligned}$
PARTENAIRES

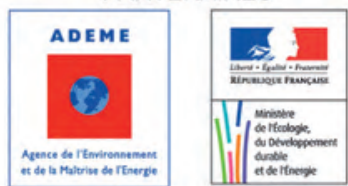

AVEC LE CONCOURS DE

D meteo france 